\title{
Powder Stream Characteristics in Cold Spray Nozzles
}

\author{
R. Lupoi and W. O’Neill \\ Institute for Manufacturing, Department of Engineering, University of Cambridge \\ 17 Charles Babbage Road, CB3 0FS, Cambridge (UK) \\ Corresponding author is R. Lupoi \\ e-mail: r1372@cam.ac.uk \\ phone: (+44)01223764617 fax: (+44)01223464217
}

\begin{abstract}
The exponential increase of industrial demand in the past two decades has led scientists to the development of alternative technologies for the fast manufacturing of engineering components, aside from standard and time consuming techniques such as casting or forging.
\end{abstract}

Cold Spray (CS) is a newly developed manufacturing technique, based upon the deposition of metal powder on a substrate due to high energy particles impacts. In this process, the powder is accelerated up to considerable speed in a converging-diverging nozzle, typically using air, nitrogen or helium as a carrier gas. Recent developments have demonstrated significant process capabilities, from the building of mould-free 3D shapes made of various metals, to low porosity and corrosion resistant titanium coatings.

In the CS process, the particle stream characteristics during the acceleration process is important in relation to the final geometry of the coating. Experimental studies have shown the tendency of particles to spread over the nozzle acceleration channel, resulting in a wide exit stream and in the difficulty of producing narrow tracks.

This paper presents an investigation on the powder stream characteristics in CS supersonic nozzles. The powder insertion location was varied within the carrier gas flow, along with the geometry of the powder injector, in order to identify their relation 
with particles trajectories. Computational Fluid Dynamic (CFD) results by Fluent v6.3.26 are presented, along with experimental observations. Different configurations were tested and modelled, giving deposited track geometries of copper and tin ranging from $1 \mathrm{~mm}$ to $8 \mathrm{~mm}$ in width on metal and polymer substrates.

Keywords: Computational Fluid Dynamics, Cold Spray, Powder stream, Narrow coatings, Polymers.

\section{INTRODUCTION}

The development of manufacturing processes is most definitely a very active research field, which has increasingly attracted the interest of scientists and institutions. Relatively simple techniques such as casting or forging have been widely implemented since the industrial revolution for large scale production, and nowadays still play an important role in the world-wide manufacturing industry.

However, the increasing demand of high quality products and friendly industrial environments is driving the attention away from ordinary means of manufacturing, to focus research efforts on the development of alternative technologies. During the last two decades, new methods have been introduced, with the potential of providing a step change to standard industrial processes. One example is Rapid Prototyping (RP) [1], a method capable of the automatic construction of 3D physical objects using additive manufacturing technology. In this process the shape of the final product is simply modelled with a 3D-CAD software, and then automatically built layer by layer throughout the employment of various techniques such as Fused Deposition Modelling (FDM), Stereolithography (SL) or 3D-printing (3DP). Laser material processing [2] is another example of a manufacturing technology recently developed, and based upon the employment of a wide range of lasers to perform conventional operations such as 
marking, cutting, drilling and welding. The advantages of using lasers for manufacturing operations can be various, from a total reduction of cutting forces to a much higher level of process efficiency and final product quality. Another method, recently patented by Alkhimov [3] and known as Cold Spray (CS), has widely attracted the interest of industry. In this process [4], material (typically metal) in a powder form is injected within a supersonic gas stream (carrier gas). Particles travelling at such high speed are shown to deposit upon impact with a substrate material, and form a coating. Carrier gases are typically helium or nitrogen, accelerated up to supersonic velocities through converging-diverging nozzles. Helium is a relatively expensive gas, but it is capable of generating velocity magnitudes in the order of thousands meters per second due to its high sonic speed. Pattison et al. [5] have explored the potential of Cold Spray to fabricate mould-free 3D geometries, and successfully produced prototype components made out of titanium, aluminium and copper with helium as carrier gas. Optimum particle velocity requirements to form a deposit have been extensively studied, against their size and material [6,7]. On the other hand, Bray et al.[8] have further improved the process with the integration of a laser apparatus in the system. In this case, a laser beam is fired on the substrate surface during the spraying process, in order to provide extra energy in the form of heat to the impingement zone, and facilitate bonding.

Particles can be injected in the carrier gas either across the nozzle inlet region or downstream the throat. In the first configuration, higher final velocities can be reached as they are entrained in the jet stream for a longer period of time, however high pressure feeders are necessary and when spraying with elevated gas temperatures the design of the powder injector becomes more complex to avoid clogging [9]. On the other hand, 
particles releasing downstream the nozzle throat (low pressure and temperature zone) is a more practical solution, but the achievable impact speed reduces [10].

It is however not fully understood how the particle in-flight distribution and footprint on a substrate is affected by the nozzle type and powder injection location. In Cold Spray (CS), the geometry of the high speed powder stream which exits the nozzle is important in relation to the final shape and achievable size of the deposited coating. Typically, powder footprints on a substrate are in the $>4 \mathrm{~mm}$ diameter range. Recent work by Yin et al. [11] and Tabbara et al. [12] have initialized studies through CFD modelling of particle acceleration and distribution with different nozzles cross-sections with upstream powder injection. Elliptical, spherical and square shapes were examined. Each of them gave dissimilar results, however experimental observations were not reported against footprints predictions.

Specifically, the potential generation of narrow geometry streams by CS is of particular interest. It could be achieved through the implementation of aerodynamic lenses $[13,14]$, however their acceleration up to supersonic velocity to obtain deposition upon impact against a substrate has not been fully investigated. The possibility of producing and simulate narrower particle streams on non-metallic substrate types would enable the implementation of this technology in the electric, electronic and aerospace industry. Current technologies are time consuming (masking or pre-surface treatments are typically necessary), therefore inefficient.

This paper presents results from a Computational Fluid Dynamic (CFD) investigation on powder stream characteristics against different supersonic nozzles types, powder injection locations and apparatus. The Lagrangian (one way coupling) Discrete Phase Modelling (DPM) algorithm implemented in Fluent v6.3.26 was used in this study. Numerical results by the CFD analysis are also compared against experimental 
observations when spraying copper and tin powder onto metallic and polymer substrates.

\section{COLD SPRAY SYSTEM}

A schematic diagram of the in-house Cold Spray system working principles developed in the University of Cambridge is shown in Figure 1. The spraying gun of the system comprises of a supersonic converging-diverging nozzle and a powder injector. In operating conditions, a pressurized carrier gas is fed through a number of ports, to enter the nozzle inlet zone of length $a$. At the same time, a mixture of gas and powder is delivered form a powder feeder to the powder injector shown in the figure. The carrier gas will therefore expand up to atmospheric pressure and accelerate throughout the main nozzle total length $(a+b)$, giving sonic velocity at correspondence of the throat and supersonic speed at the exit. Particles are dragged by the carrier gas up to high velocity magnitudes, resulting in severe plastic deformation processes upon impact with a solid substrate positioned at the distance SoD (Standoff Distance). As a consequence, bonding with the substrate can occur and the coating process can be initiated. The substrate is connected to a CNC table to allow for movement along the $X$ and $Y$ direction at an imposed speed, in such a way to control and shape the coating accordingly.

The carrier gas used in this system is nitrogen, delivered with a maximum static pressure of 30bar from Multiple Cylinders Pallet (MCP) sources. The actual level of pressure at the nozzle can be adjusted through a computer controlled regulator. A highpressure powder feeder (Praxair 1264HP, wheel type) is implemented to deliver particles into the nozzle inlet. Typical particle sizes optimal for Cold Spray applications are within the range $10 \mu \mathrm{m}$ to $60 \mu \mathrm{m}$ diameter. The supersonic nozzle internal profile of the supersonic section of length $b$ is critical with respect to the system performance. A 
De-Laval geometry (simple conical converging-diverging) is usually preferred to more complex shapes for easiness of manufacture. A typical design is characterized by a circular cross-section nozzle (axial-symmetric) with a $2 \mathrm{~mm}-6 \mathrm{~mm}$ throat-exit diameter respectively, and a variable length $b$ tailored for specific applications. In longer nozzles particles are entrained in the jet stream for longer periods, therefore the impact velocity is higher. In the current system, the maximum achievable carrier gas velocity (room temperature inlet conditions) is in the order of $650 \mathrm{~m} / \mathrm{s}$ with a De-Laval nozzle $(b=180 \mathrm{~mm})$, giving a particle impact speed in the range between $300 \mathrm{~m} / \mathrm{s}$ and $550 \mathrm{~m} / \mathrm{s}$, depending on feedstock powder type of material and size. Smaller particles and lightweight materials would travel faster in comparison to larger geometries and heavier metals.

Supersonic nozzles implemented in the system are manufactured in tool steel; current designs are polished up the achievement of a minimum surface finish of $0.5 \mathrm{Ra}$ on the bore contour. They can also be heat-treated to reach a required level of hardness, in order to avoid erosion due to particles abrasion against the nozzle channel internal surface.

\section{CFD SIMULATION OF COLD SPRAY NOZZLES}

The design of the supersonic nozzle acceleration channel is certainly most critical in the Cold Spray process. It dictates the exit carrier gas velocity, i.e. particles speed, for given inlet and outlet conditions. Also, nozzles are costly components to manufacture as tight tolerances are required in supersonic regimes. With this respect, it is fundamental to accurately predict their performance based on theoretical calculations. The Quasi-OneDimensional flow theory and the Method of Characteristics $[15,16]$ provide insights into the basic principles of nozzles contours for compressible flows. However, with the development of advanced numerical techniques such as Computational Fluid Dynamics 
(CFD), the study of other relevant parameters such turbulence generation-dissipation within the jet flow and the addition of multi-phase capabilities is nowadays achievable. Fluent (version 6.3.26) commercial software was used in this work to predict the performance of the Cold Spray nozzles analyzed, combined with a study of particles trajectories and velocity within the jet flow. Samareh et al. [17] have studied through a two-way coupling system the behaviour of particles in CS nozzles and effects on gas velocity for high particle loadings (60 to $180 \mathrm{~g} / \mathrm{min}$ ), and by implementing advanced multiple equations turbulence models. Such models can be accurate, but are relatively difficult to consistently converge up to higher order schemes; also the loading of particles within the carrier gas in most Cold Spray applications is typically smaller, therefore within the range of sufficiently diluted flow (solid phase volume fraction $<10 \%$ ) $[12,18]$; particle-particle and particle-carrier gas interactions can be negligible. As a consequence, a Lagrangian (one way coupling) solution given by the Discrete Phase Model (DPM) algorithm implemented in the code can be sufficiently accurate, and was used in this work to provide information on powder stream characteristics, and subsequently compared against experiments. The "high-mach-number" drag law was applied in the simulations. In order to take into account for particle dispersion due to turbulence effects, the Stochastic-Tracking type model implemented in Fluent was used. In this approach, the Discrete Random Walk (DRW) model is used to predict the fluctuating components of the total particle velocity and effects on its trajectory [18]. When the path is computed for a sufficient number of times, a realistic prediction of the random effects by turbulence on particle dynamics can be achieved.

Solutions in a Lagrangian reference frame for particle motions in supersonic flow with Fluent and the high mach number drag law have been published in the recent past, over flat and round substrates geometries [19,20]. In particular, Bray et al.[8] observed that 
particle velocity predictions were in close agreement against experimental observations $(<5 \%)$ at variable nozzle inlet conditions.

A steady-state solution for the carrier gas flow was obtained with the density-based solver, which better adapt to supersonic regimes in comparison to the more conventional pressure-based. The density of the fluid is computed through the ideal gas law, therefore it is not assumed constant. Flows were modelled in $2 \mathrm{D}$ through the double precision method (2ddp) and the "axial-symmetric" option was enabled; as a consequence the 2D governing equations in axial-symmetric form were solved. Convergence was achieved up to the second-order scheme in all cases.

The geometry was meshed by using Gambit 2.2.30, with structured elements over the entire domain. In order to achieve a grid independent solution, a variable number of cells between 50000 and 120000 was required, depending on the nozzle type and overall size. The nozzle inlet and outlet surfaces, located where Figure 2 shows, were set as pressure-inlet (giving the value of the actual operating pressure) and pressure-outlet (correspondent to static atmospheric conditions) boundaries. It is important to locate the outlet boundary far enough from the nozzle exit cross-section so not to impose unrealistic settings. As the flow is bounded within an axial-symmetric wall and does not exhibits rapid changes of direction for nearly the entire domain, the k- $\varepsilon$-realizable two equations turbulence model was employed in all cases. The substrate was modelled as a rigid surface at the distance $S o D$ from the nozzle exit location.

\section{PARTICLES STREAM ANALYSIS}

\subsection{Spray configurations}

Figure 3 (a) and (b) show the spray nozzles and powder injectors used for the experiments presented in this paper. Four configurations were tested, named as (1), (2), 
(3) and (4) respectively. Geometrical and optimum operating parameters for each configuration are summarized in Table 1.

In configuration (1) the powder is injected in the inlet zone of the nozzle, therefore before the throat, through a $2 \mathrm{~mm}$ inner diameter powder injector included in the figure. Due to its long length, it can be observed from the figure that the nozzle geometry was reduced in diameter near its exit to avoid physical contact against other equipment installed in the CS system. Configuration (2) is similar to (1) as they share the same injector geometry, however the nozzle in this case is characterized by a shorter supersonic length and wider exit cross-section. On the other hand, in configuration (3) the injector is longer than in (1) and (2) and accommodated through the nozzle throat concentrically when in operation, to allow for powder release in the axial direction and in the lower pressure supersonic region of the nozzle. In this configuration, the injector exit is placed at a distance of $50 \mathrm{~mm}$ from the throat. Configuration (4) comprises of a relatively short nozzle, with a powder injector of $0.5 \mathrm{~mm}$ inner diameter mounted concentrically as for configuration (3). Its exit is also located in the nozzle supersonic region, but nearer to the nozzle throat $(0.8 \mathrm{~mm}$ distance $)$. As shown in Figure 3(b), the outer geometry of the injector is shaped conical for this configuration, to optimize the carrier gas dynamics.

\subsection{Numerical and experimental results}

Figure 4 shows contour plot results of velocity magnitude for the configuration (1) apparatus, at correspondence of the inlet and outlet regions. The actual pressure-inlet boundary surface was made wider than the real inlet section from Figure 3(a), in order to simulate static conditions and facilitate numerical convergence. The injection port pressure was set to 30.4 bar, to generate a mass flow rate of approximately $20 \%$ the main 
nozzle. This condition falls within the optimum range for the current CS system to generate a consistent powder flow from the feeder. The gas maximum velocity is $674.6 \mathrm{~m} / \mathrm{s}$, giving a supersonic flow approximately 3.5 times faster than the speed of sound. The nozzle is shown to be over-expanded, therefore oblique shock waves develop at the exit. The $S o D$ between nozzle exit and substrate was set to $40 \mathrm{~mm}$. On the other hand, Figure 5 shows the velocity contour detail at correspondence of the injector exit, where the two gas streams intersect. Nitrogen flowing out the injector is therefore revealed to travel faster.

Particles enter the CFD domain through the injection port, shown in Figure 4 and 6. In the experimental CS system, such port is coupled to a relatively long and straight hose (6mm inner diameter) connected at one end to the powder feeder. It is therefore sensible to assume that particles enter the grid axially, i.e. with a negligible velocity radial component. The Computational results suggest that after particles are released through the injection port $(20 \mu \mathrm{m}$ spherical copper is simulated), their trajectories does not stay close to the nozzle centreline, but diverge to occupy approximately the entire volume of the nozzle channel, as shown in Figure 6, at correspondence of the outlet region. Therefore the cross-sectional geometry of the particle stream is comparable in size to the nozzle exit.

Reasons for such behaviour can be various and difficult to assess. However, main causes seem to originate in the inlet region, where particles delivered by the powder feeder approach the injector zone. They are observed not to follow the gas stream where the cross-section reduces due to inertial effects, at the interception between powder feeder and injector lines (rebound wall 1 in Figure 6), and to significantly rebound against channel walls in this location. Tangential and normal rebounding coefficients are set to be 1 in this study, i.e. elastic impacts are assumed to occur. The same 
assumption was made by Nguyen et al. [21] in the study of solid particles interactions (10 to $100 \mu \mathrm{m}$ diameter) with wall surfaces in gas-particulate flows. Thus, most particles enter the injector deflected, and exit from it with an angled velocity as Figure 6 shows. In this zone, the particles stream assumes a shape similar to a cone. As a consequence, further impacts against the nozzle wall at correspondence of the throat are unavoidable (rebound wall 2 zone), resulting in additional deflections and in the generation of a notuniform and dispersed stream in the outlet region.

Also, turbulence generated by the carrier gas in the nozzle is important and is shown to have an additional effect on particles trajectories. In this respect, Figure 7 shows the computed specific turbulence kinetic energy against the nozzle centreline. Simulations results shows that the turbulent activity increases as the gas accelerate in the inlet region of the nozzle. A peak is observed nearby the throat. However, when the flow becomes supersonic the dilatation-dissipation effect [22] is predominant and the turbulent activity diminishes. When particles cross the throat, they are still relatively low in speed and momentum; therefore their trajectory is most likely to be affected and further mixed by the higher turbulence activity generated in this region. Gas turbulence effects on particles is included in results from Figure 6. When turbulence is not taken into account in the formulation of particles trajectories, the final stream geometry at the nozzle outlet reduces of approximately $42 \%$, giving an apparently more focused beam for the size and material investigated (20 $\mathrm{m}$ copper); therefore confirming a significance difference in final results.

Also, to simulate the potential effect on particles stream geometry by a variable injection port (shown in Figure 4 and 5) pressure, additional simulations were solved at set values of 32bar and 35bar(maximum allowable in the feeder). Negligible differences 
were observed, in fact the stream tend to occupy the entire volume of the nozzle channel in all cases.

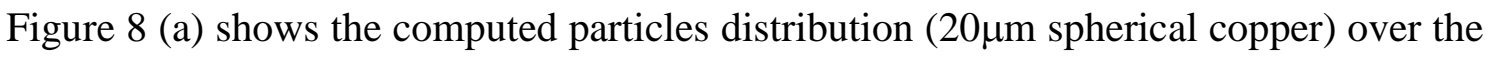
substrate surface area. Particles are observed to mostly concentrate over a zone of approximately $3.5 \mathrm{~mm}$ radius, therefore their footprint extend up to a region of $7 \mathrm{~mm}$ diameter. However, the vast majority of the particles seem to concentrate within a $3 \mathrm{~mm}$ diameter zone. For a comparison, Figure 8(b) shows a close-up picture of an experimental metallic track on an aluminium substrate by the configuration (1) arrangement. The track was obtained from copper powder (Sandvik Osprey Ltd. / HC $\mathrm{Cu}-32+10 \mu \mathrm{m}$ spherical). The powder size set in the CFD model corresponds to the average size by the commercial range. The measurement of the overall track width $(6.5 \mathrm{~mm})$ compares well with the predicted powder beam distribution on the substrate by the numerical analysis. Also, the cross-section profile measurement of the track in Figure $8(b)$ has revealed the coating is approximately $17 \%$ thicker nearby the centreline, for a region measuring $4 \mathrm{~mm}$ in width. This is also in agreement with the numerical analysis, as the vast majority of the particles are predicted to concentrate within the $3 \mathrm{~mm}$ diameter zone. A 3D model of this configuration was also developed; similar results were observed against the $2 \mathrm{D}$ axial-symmetric case, however for a much higher computational time.

In similar ways, a model of the configuration (2) system was developed. In this case, the injection port inlet pressure was set to $31 \mathrm{bar}$, to give a mass flow rate of approximately $20 \%$ the main nozzle, as for configuration (1). The system has shown a comparable performance against the previous arrangement. The computed copper powder stream geometry in the outlet region is shown in Figure 9, coloured by particles velocity magnitudes. Figure 10(a) shows the powder distribution across the substrate surface for 
this configuration. The stream is more uniformly distributed in comparison with the previous case and a larger footprint of over $10 \mathrm{~mm}$ diameter is predicted; however only a small rate of particles seems to collide in the region between $4 \mathrm{~mm}$ and $5 \mathrm{~mm}$ diameter. The nozzle was experimentally tested, and a track width of $8 \mathrm{~mm}$ was measured as shown in Figure 10(b). Also in this case experimental observations are comparable with numerical results. Due to the relatively short acceleration channel $b$ of the nozzle described in configuration (2), the deposition velocity of copper could only be achieved with a longer $S o D$, so that to increase the residence time of particles within the jet flow, i.e. their impact speed. For this reason the $S o D$ was set to $100 \mathrm{~mm}$, in both the experimental and numerical analysis. Results from configurations (1) and (2) have therefore highlighted the general difficulty of obtaining narrower particle streams from CS nozzles under standard geometrical and processing parameters.

Figure 11 shows particles computational results for the third spraying system arrangement, configuration (3). In this case, powder is injected axially and in the low pressure supersonic region of the nozzle, therefore after the throat at a distance of $50 \mathrm{~mm}$ from it. Tin powder (spherical, $20 \mu \mathrm{m}$ particles diameter) was simulated for this configuration. A close-up image of the gas velocity field is shown in Figure 12, at correspondence of the location where the two streams from the powder injector and main carrier gas intersect. The injector stream travels at considerable higher speed in comparison against configuration (1) and (2), however still largely lower than the supersonic carrier gas. As a consequence to this type of mixing, shock waves develop at the injector exit, as the figure shows. The prediction of turbulence kinetic energy at this location gives a value almost double than the highest from Figure 7. Such effects are unavoidable, but numerical studies have shown that it can be minimized with a tailored 
design of the injector external geometry, shown in Figure 12, and by a specific port inlet pressure (set to 5 bar in this case).

Numerical results for configuration (3), plotted in Figure 11 and 13(a), give a stream diameter of $1.6 \mathrm{~mm}$ for a $20 \mu \mathrm{m}$ particles jet; therefore 2.8 times smaller than the nozzle exit diameter and largely narrower than the previous configurations investigated. Despite a predicted higher level of turbulence, particles exit the injector at enhanced velocity relative to configurations (1) and (2), approximately 6 times faster for the same size and material, therefore with sufficient momentum to maintain a rather straight trajectory. The $S o D$ was set to $100 \mathrm{~mm}$. Also, as shown in Figure 13(a), the particles velocity distribution over the track radius $R$ is more uniform than in the previous cases, and averages up to a speed of nearly $300 \mathrm{~m} / \mathrm{s}$, which locates within the optimum deposition velocity window for this type of material [6].

The configuration (3) setup was experimentally tested with tin as feedstock powder material (Sandvik Osprey Ltd. / SC10 $-32+10 \mu \mathrm{m}$ spherical), which was sprayed to form a track onto a polymer substrate for this case, a commercial PC/ABS blend. Spraying metals onto plastic material with Cold Spray presents several difficulties, however recent work has revealed its suitability, parameters window, and deeper insights [23,24]. Experimental observations have revealed the deposition mechanism is similar to the metal to metal case [25]. Figure 13(b) shows results observed with such arrangement. The average track width was $2.9 \mathrm{~mm}$ against a computational prediction of $1.6 \mathrm{~mm}$ from Figure 11(a).

In such case of a narrower width, the overall powder flow rate requirement certainly reduces as particles are concentrated in the centreline; also chocking of the injector is likely to occur for typical CS powder loads due to its smaller cross-sectional area. In this respect, it was necessary to reduce down to a minimum the feeder speed to limit the 
amount of powder delivered. However, working below its optimum level has resulted in the generation of a not continuous flow. For such reason the coating boundaries did not appear of regular geometry as for configurations (1) and (2).

Analogous results were observed when testing configuration (4). The same tin power as in configuration (3) was simulated, however in this case the main nozzle was considerably shorter and the injector exit $(0.5 \mathrm{~mm}$ inner diameter) was located in the supersonic region on the nozzle at the reduced distance of $0.8 \mathrm{~mm}$ from the throat. However, setting of the $S o D$ up to $70 \mathrm{~mm}$ ensured the achievement of the tin deposition velocity at impact.

The average particle speed was in the $320 \mathrm{~m} / \mathrm{s}$ region, as shown in Figure 14. On the other hand, Figure 15 illustrates the velocity plot at the vicinity of the powder injector exit. A similar behaviour to configuration (3) is observed, therefore shockwaves develop; at the same time the specific turbulent kinetic energy approaches $300 \mathrm{~m}^{2} / \mathrm{s}^{2}$ in the zone. In this configuration, the smallest particles stream geometry was observed when setting the injection port inlet pressure up to 10bar. Particles are predicted to exit the injector at a speed about 4.5times higher than in configuration (1) and (2).

In such working conditions, the CFD model gave a predicted particle footprint on the substrate of $0.64 \mathrm{~mm}$ diameter as from Figure 16(a). In this case experimental observations in Figure 16(b) have revealed a measured track width of $1 \mathrm{~mm}$.

Experimental results from configurations (3) and (4) suggest that the achievement of a narrower particle stream may be accomplished through the employment of smaller diameter injectors with the exit placed in the supersonic region of the nozzle to minimize dispersion due to turbulence, alongside with tailored nozzles and working parameters. However, theoretical forecasts in this analysis from the commercial CFD package used in this work underestimate the particles footprint size in both cases. A 
reason for such behaviour could rely upon particle to particle interactions, which may be not negligible when the particles trajectories are forced to stay closer, resulting in probable contact and subsequent additional dispersion due to rebounding effects.

CFD analysis results from the configurations investigated are summarized in Table 2. The table reports the stream footprint diameter on the substrate for $20 \mu \mathrm{m}$ particle size from Figures 8,10,13 and 16. Predictions when using the smaller and larger diameter in the commercial feedstocks, i.e. $10 \mu \mathrm{m}$ and $32 \mu \mathrm{m}$, are also included. Diameter values are similar, however different. It can be therefore observed that each of the particle geometry spreads around the nozzle cross-section in a dissimilar way. Despite the larger number of particles in a commercial feedstock is typically close to the average diameter, narrower size ranges may provide a not negligible advantage for a more accurate prediction, system design and performance.

\section{CONCLUSIONS}

Cold Spray (CS) is a novel coating technology, based upon high speed impacts of particles against a substrate material, accelerated by a carrier gas. The design of the supersonic nozzle implemented in the system is critical with respect to process efficiency and coating geometry. In this paper, four nozzles configurations were examined, characterized by various acceleration channel lengths and powder injectors geometry and locations. When powder is released axially and upstream the nozzle throat, particles trajectories do not stay close to the centreline, but tend to spread over the entire volume of the channel. The particle stream diameter at impact with the substrate is comparable against the nozzle exit cross-section diameter. A theoretical (CFD) analysis has shown that main causes for this effect are a relatively high gas turbulence level generated at the vicinity of the nozzle throat which affects particles trajectories, and particles deflections due to impacts against channel walls. The 
formation of a narrower beam can be achieved through the employment of smaller diameter injectors and downstream systems. A $1 \mathrm{~mm}$ track width was obtained over a PC/ABS commercial blend polymer substrate, when using a nozzle and powder injector of $3.8 \mathrm{~mm}$ and $0.5 \mathrm{~mm}$ exit diameters respectively. The particles stream geometry by the CFD results compares well against experimental observations. On the other hand, when powder is released axially and straight into the supersonic region of the nozzle, computational simulations by the commercial package used are in accordance with the experiments, but were unable to provide an accurate prediction of the powder stream geometry. The use of commercial powders characterized by a narrower size range may provide a not negligible advantage for a more accurate system design and performance.

\section{ACKNOWLEGMENTS}

The authors wish to express their gratitude to the Technology Strategy Board (TSB), Haswell Moulding Technologies Ltd., Quality Plated Plastics Ltd., Industrial Finishing Systems (Midlands) Ltd., Dyne Technology Ltd., GKN Aerospace Services Ltd., Hybrid Innovations Ltd. and Pera Innovation Ltd. for providing valuable industrial support and contribution to the development of this work.

\section{REFERENCES}

[1] C.K. Chua, K.F. Leon, C.S. Lim "Rapid prototyping principles and applications", World Scientific Publishing Co., 2003.

[2] W. M. Steen "Laser material processing”, Springer, 2003.

[3]A.P. Alkhimov, V.F. Kosarev, N.I. Nesterovich, A.N. Papyrin "Method for deposition of coatings, Patent, SU1618778, 1991.

[4] A. Papyrin, V. Kosarev, K.V. Klinkov, A. Alkhimov, V.M. Fomin "Cold Spray Technology" Elsevier, 2006. 
[5] J. Pattison, S. Cellotto, R. Morgan, M. Bray, W.O’Neill "Cold gas dynamic manufacturing: A non-thermal approach to freeform fabrication", International Journal of Machine Tools and Manufacture, 47, 3-4, 2007, 627-634.

[6] T. Schmidt, H. Assadi, F. Gartner, H. Richter, T. Stoltenhoff, H. Kreye, T. Klassen, "From particle acceleration to impact and bonding in cold spraying", Journal of Thermal Spray Technology, 18(5-6), 2009, 794-808.

[7] H. Assadi, F. Gartner, T. Stoltenhoff, H. Kreye "Bonding mechanism in cold gas spraying", Acta Materialia, 51, 15, 2003, 4379-4394.

[8] M. Bray, A. Cockburn, W. O'Neill "The laser assisted cold spray process and deposit characterization", Surface \& Coatings Technology, 203 (2009), 2851-2857.

[9] T.Han, B.A. Gillispie, Z.B. Zhao "An Investigation on powder injection in the HighPressure Cold Spray process", Journal of Thermal Spray Technology, Volume 18 (3), 2009, 320-330.

[10] X.J.Ning, Q.S. Wang, Z. Ma, H.J. Kim "Numerical Study of In-flight Particle Parameters in Low-Pressure Cold Spray Process", Journal of Thermal Spray Technology, Volume 19 (6), 2010, 1211-1217.

[11] S.Yin, X. Wang, W. Li "Computational analysis of the effect of nozzle crosssection shape on gas flow and particle acceleration in cold spraying", Surface \& Coatings Technology, 205 (2011), 2970-2977.

[12] H. Tabbara, S. Gu, D.G. McCartney, T.S. Price, P.H. Shipway "Study on Process Optimization of Cold Gas Spraying", Journal of Thermal Spray Technology, Volume 20 (3), 2011, 608-620.

[13] X. Zhang, K.A. Smith, D.R. Worsnop, J. Jimenez, J.T. Jayne, C.E. Kolb "A Numerical Characterization of Particle Beam Collimation by an Aerodynamic LensNozzle System: Part I. An Individual Lens or Nozzle", Aerosol Science and Technology, 36, 2002, 617-631.

[14] M.F.Smith, J.E. Brockmann, R.C. Dykhuizen, D.L. Gilmore, R.A. Neiser, T.J. Roemer "Cold spray direct fabrication - high rate, solid state, material consolidation", Material Research Society Symposium Proceedings, Vol. 542, 1999, 65-76.

[15] J.D. Anderson "Modern compressible flow with historical perspective", McGraw Hill, 2004 (third edition).

[16] A. McCabe "Design of a supersonic nozzle", UK Aeronautical Research Council Reports and Memoranda, No. 3440, March 1964.

[17] B. Samareh, O. Stier, V. Luthe, A. Dolatabadi "Assessment of CFD modelling via flow visualization in Cold Spray processes", Journal of Thermal Spray Technology, Volume 18 (5-6), 2009, 934-943.

[18] Fluent 6.3.26 User Guide manual. 
[19] R. Nickel, K. Bobzin, E. Lugscheider, D. Parkot, W. Varava, H. Olivier, X. Luo "Numerical Studies of the Application of Shock Tube Technology for Cold Gas Dynamic Spray Process", Journal of Thermal Spray Technology, Volume 16 (5-6), 2007, 729-735.

[20] B. Samareh, A.Dolatabaldi "A three dimensional analysis of the cold spray process: the effect of substrate location and shape", Journal of Thermal Spray Technology, Volume 15 (5-6), 2007, 634-642.

[21] A.V. Nguyen, C.A.J. Fletcher "Particle interaction with the wall surface in twophase gas-solid particle flow" International Journal of Multiphase Flow, 25(1999), 139154.

[22] S. Sarkar, G. Erlebacher, M.Y.Hussaini, H.O.Kreiss "The analysis and modelling of dilatational terms in compressible turbulence", Journal of Fluid Mechanics, 1991, $227,473-493$.

[23] A. Sturgeon, B. Dunn, S. Celotto, W.O'Neill “Cold sprayed coatings for polymer composite substrate" European Space Agency, (Special Publication), ESA SP, n616, September 2006.

[24] F.Robitaille, M.Yandouzi, S.Hind, B.Jodoin "Metallic coating of aerospace carbon/epoxy composites by the pulsed gas dynamic spraying process", Surface \& Coatings Technology, 203 (2009), 2954-2960.

[25] R. Lupoi, W.O'Neill "Deposition of metallic coatings on polymer surfaces using cold spray”, Surface \& Coatings Technology, 205 (2010), 2167-2173. 


\section{LIST OF FIGURES and TABLES}

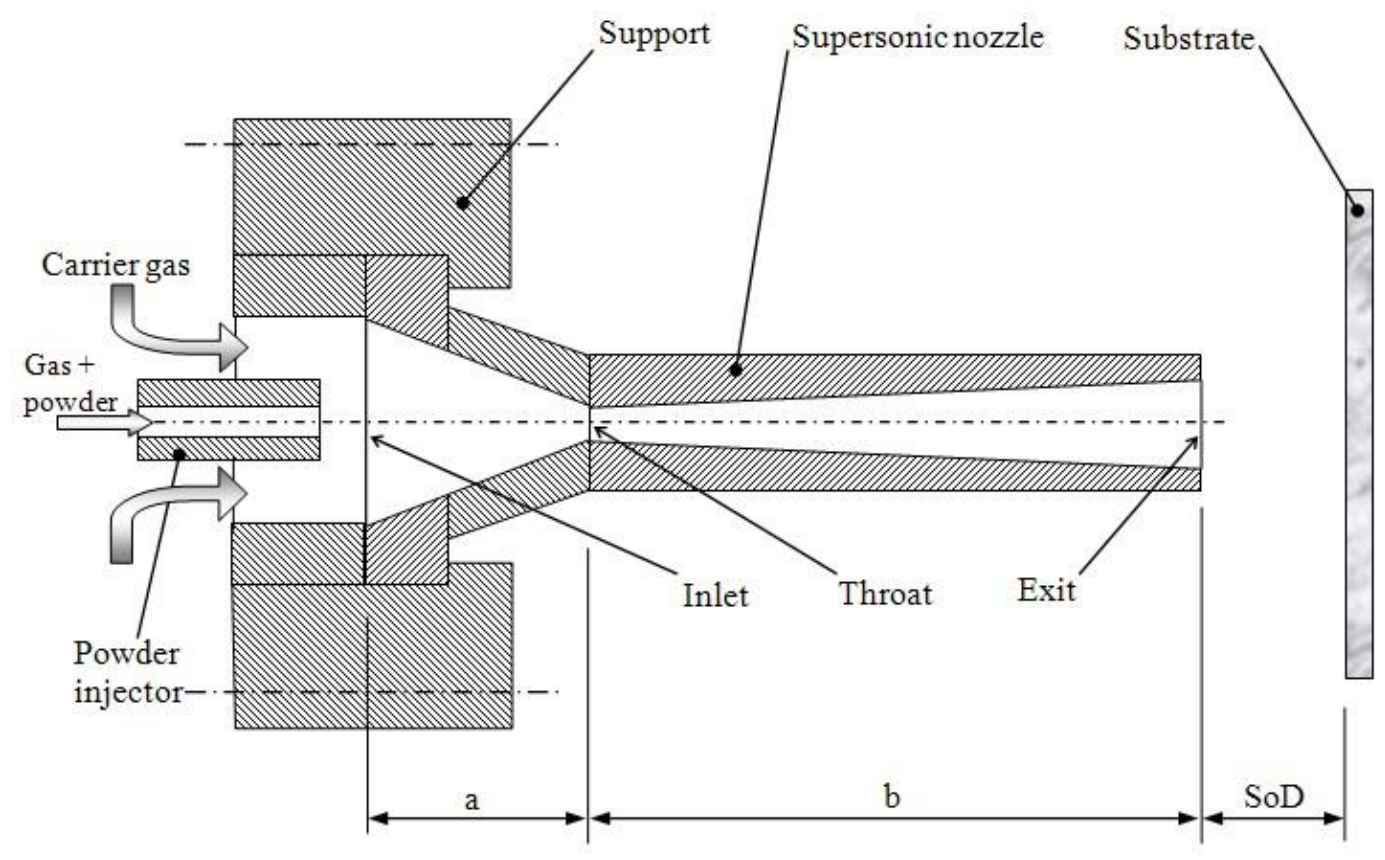

Figure 1: Cold Spray (CS) system working principles

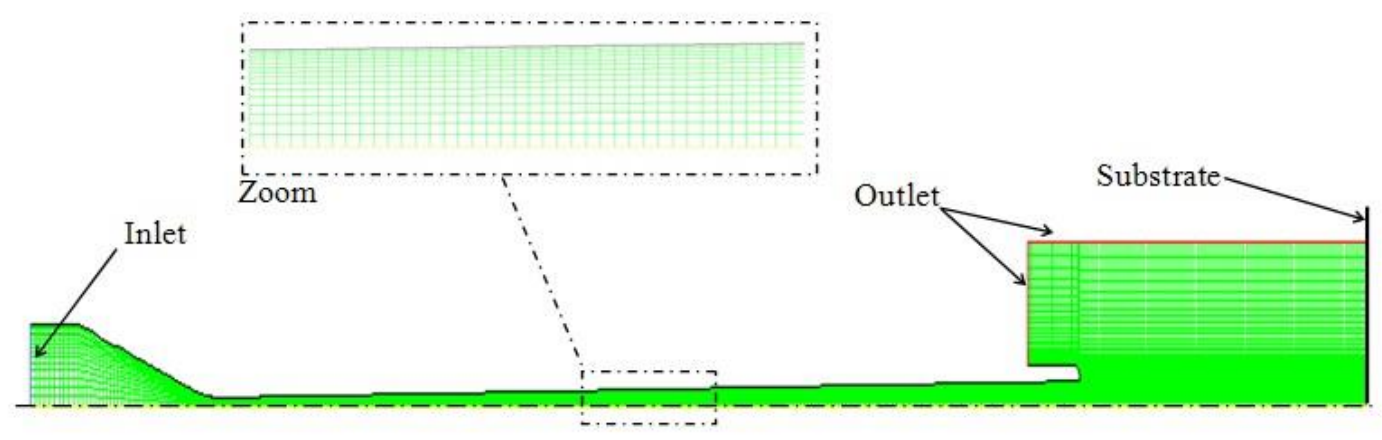


Figure 2: Modelling and meshing of an axial-symmetric supersonic nozzle with circular cross-section

(a)

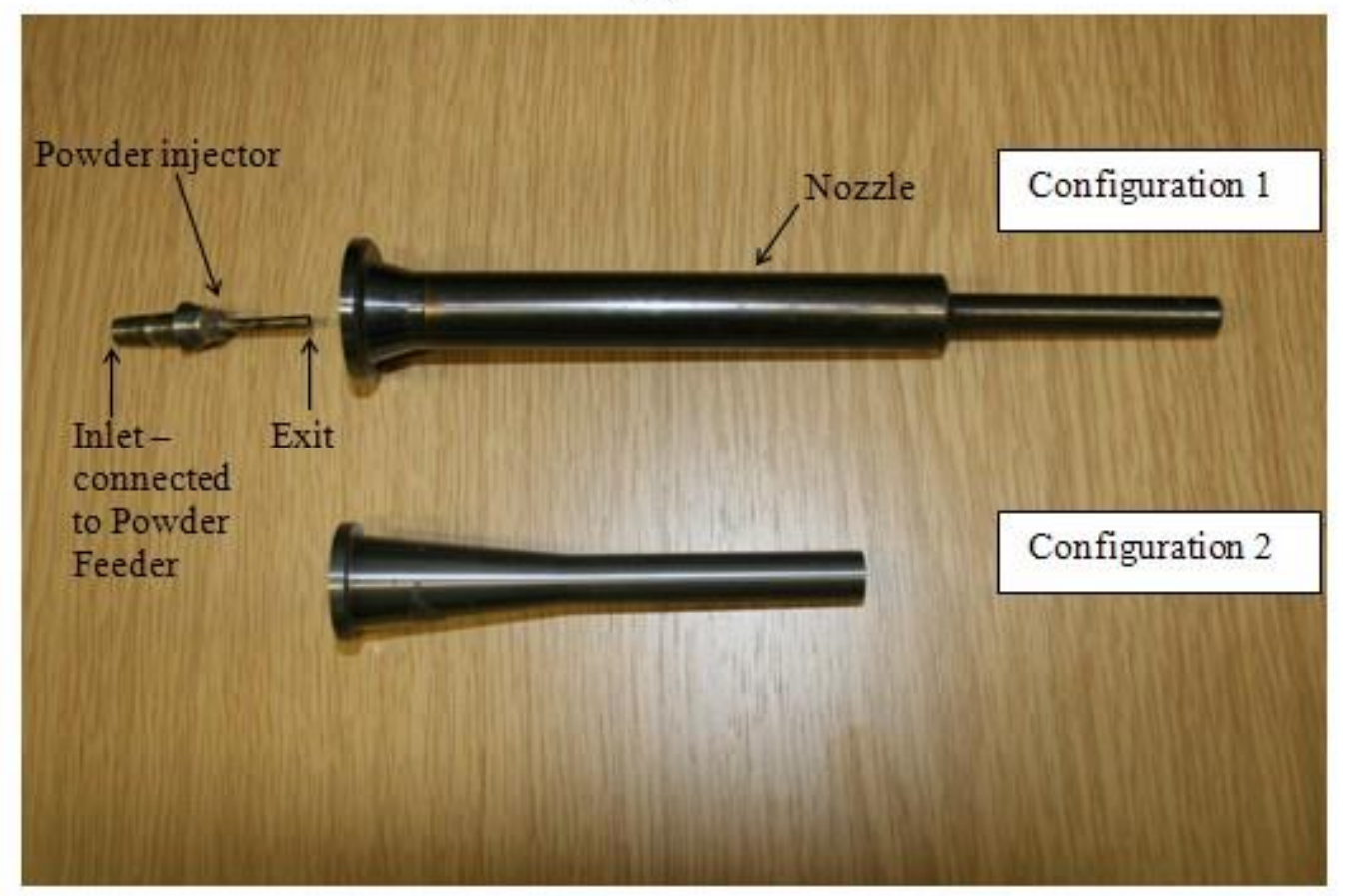

(b)

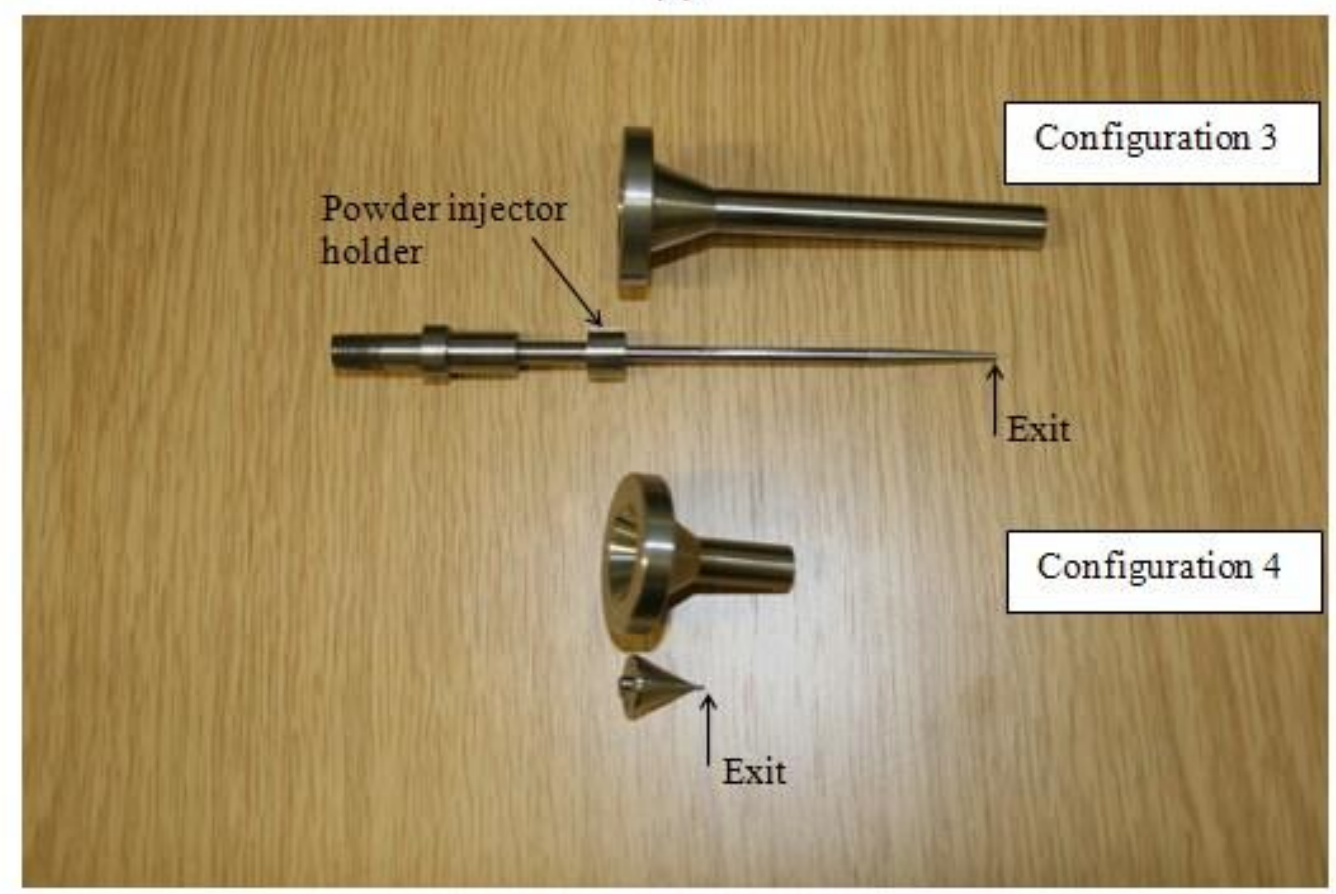


Figure 3: (a) and (b) Spray nozzles and powder injector experimental configurations

\begin{tabular}{|l|c|c|c|c|}
\hline CONFIGURATION & $\mathbf{1}$ & $\mathbf{2}$ & $\mathbf{3}$ & $\mathbf{4}$ \\
\hline Throat diameter & $2 \mathrm{~mm}$ & $2.7 \mathrm{~mm}$ & $4 \mathrm{~mm}$ & $2.2 \mathrm{~mm}$ \\
\hline Inlet diameter & $22 \mathrm{~mm}$ & $18 \mathrm{~mm}$ & $20 \mathrm{~mm}$ & $20 \mathrm{~mm}$ \\
\hline Exit diameter & $6 \mathrm{~mm}$ & $8.1 \mathrm{~mm}$ & $4.6 \mathrm{~mm}$ & $3.8 \mathrm{~mm}$ \\
\hline Inlet lenght $(a)$ & $30 \mathrm{~mm}$ & $50 \mathrm{~mm}$ & $17 \mathrm{~mm}$ & $15 \mathrm{~mm}$ \\
\hline Supersonic lenght $(b)$ & $180 \mathrm{~mm}$ & $65 \mathrm{~mm}$ & $70 \mathrm{~mm}$ & $20 \mathrm{~mm}$ \\
\hline Standoff distance $(\mathrm{SoD})$ & $40 \mathrm{~mm}$ & $100 \mathrm{~mm}$ & $100 \mathrm{~mm}$ & $70 \mathrm{~mm}$ \\
\hline Inlet static pressure & $30 \mathrm{bar}$ & $30 \mathrm{bar}$ & 30 bar & $20 \mathrm{bar}$ \\
\hline $\begin{array}{l}\text { Outlet static pressure } \\
\text { Injector exit diameter }\end{array}$ & atmospheric & atmospheric & atmospheric & atmospheric \\
\hline Injector exit location & nozzle inlet zone & nozzle inlet zone & supersonic zone & supersonic zone \\
\hline
\end{tabular}

Table 1: Configurations main working parameters

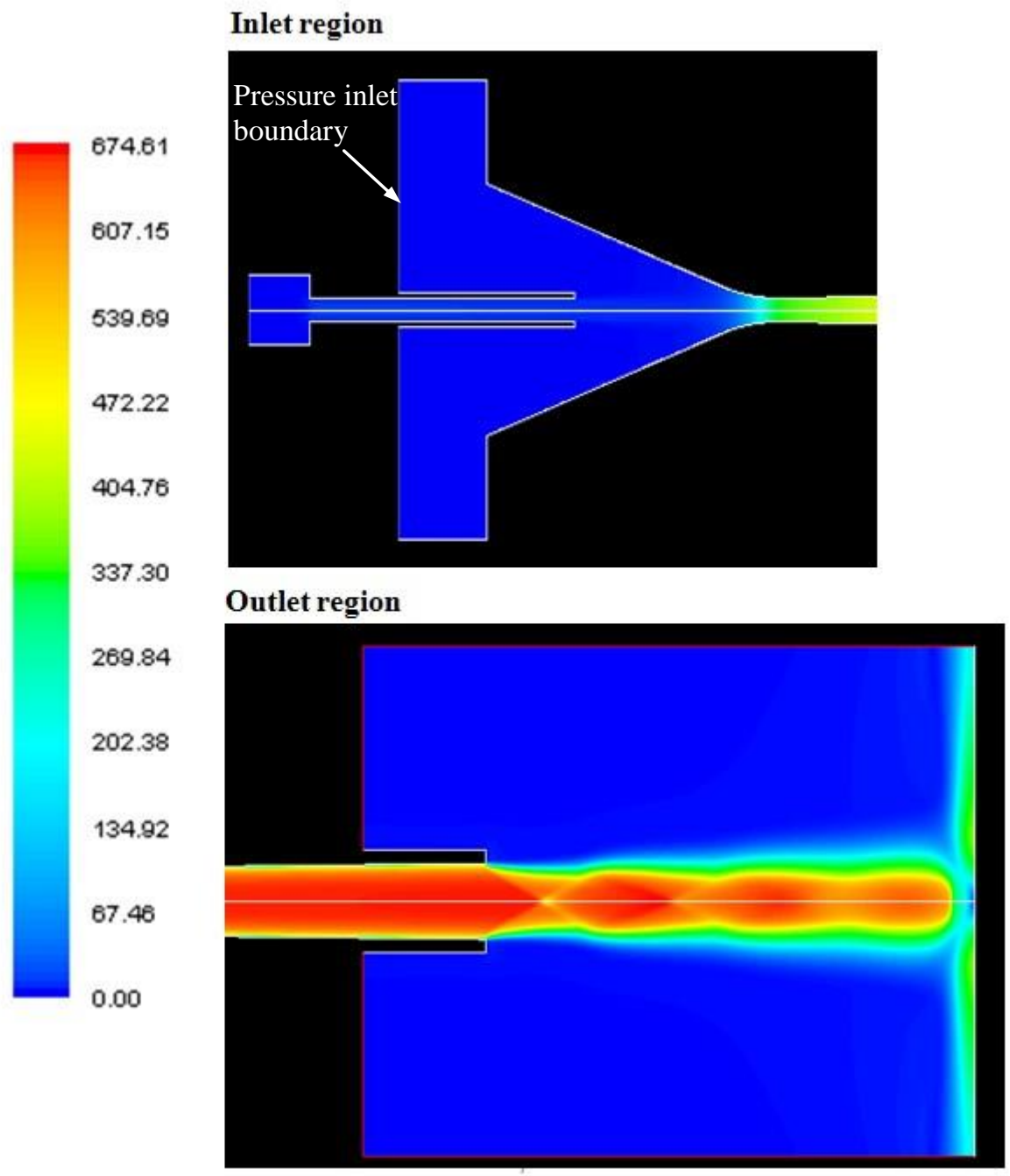


Figure 4: CFD velocity magnitude contours (m/s) at inlet and outlet - configuration (1)

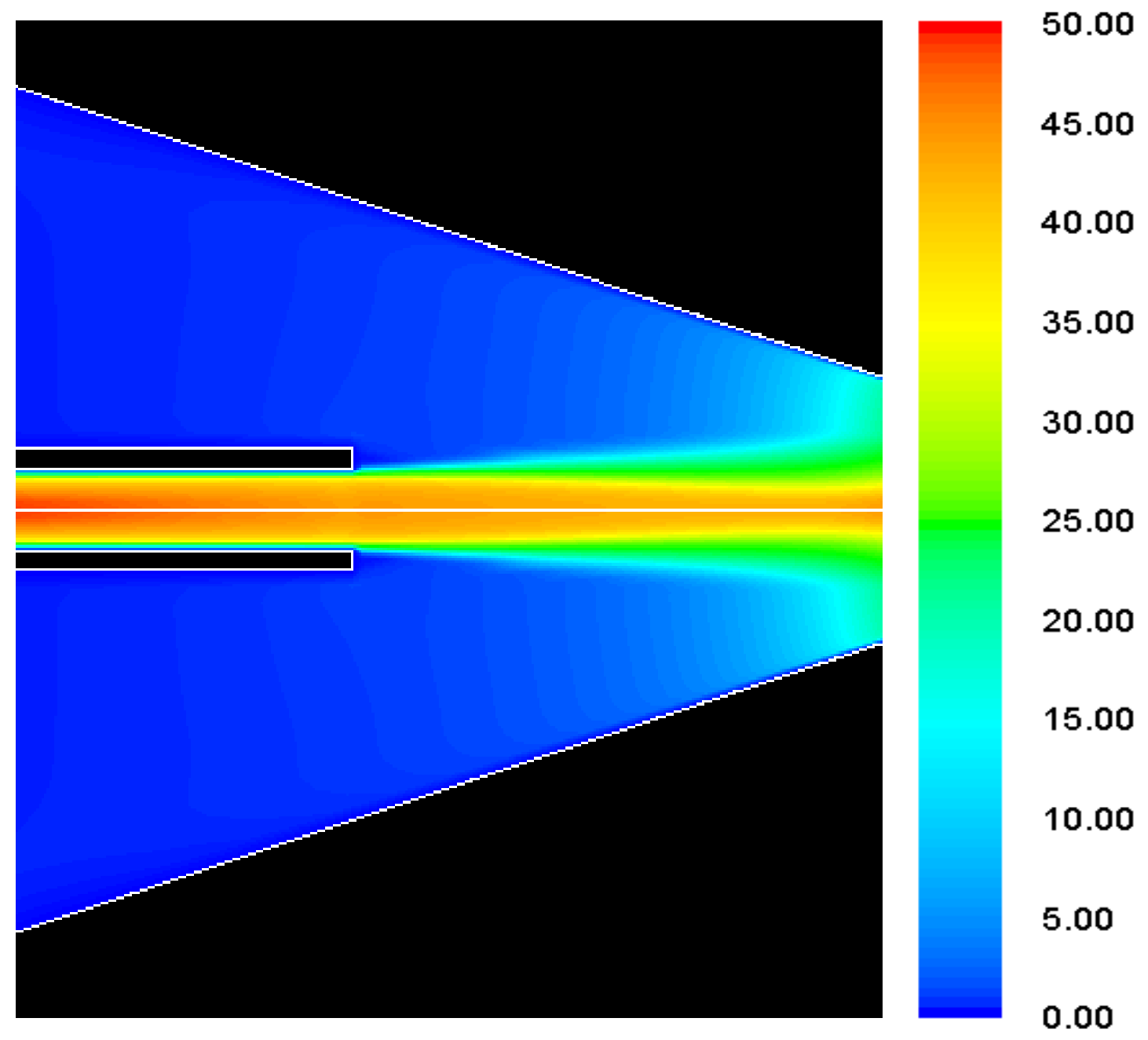

Figure 5: Plot of velocity magnitude contours $(\mathrm{m} / \mathrm{s})$ at the injector exit location configuration (1) 


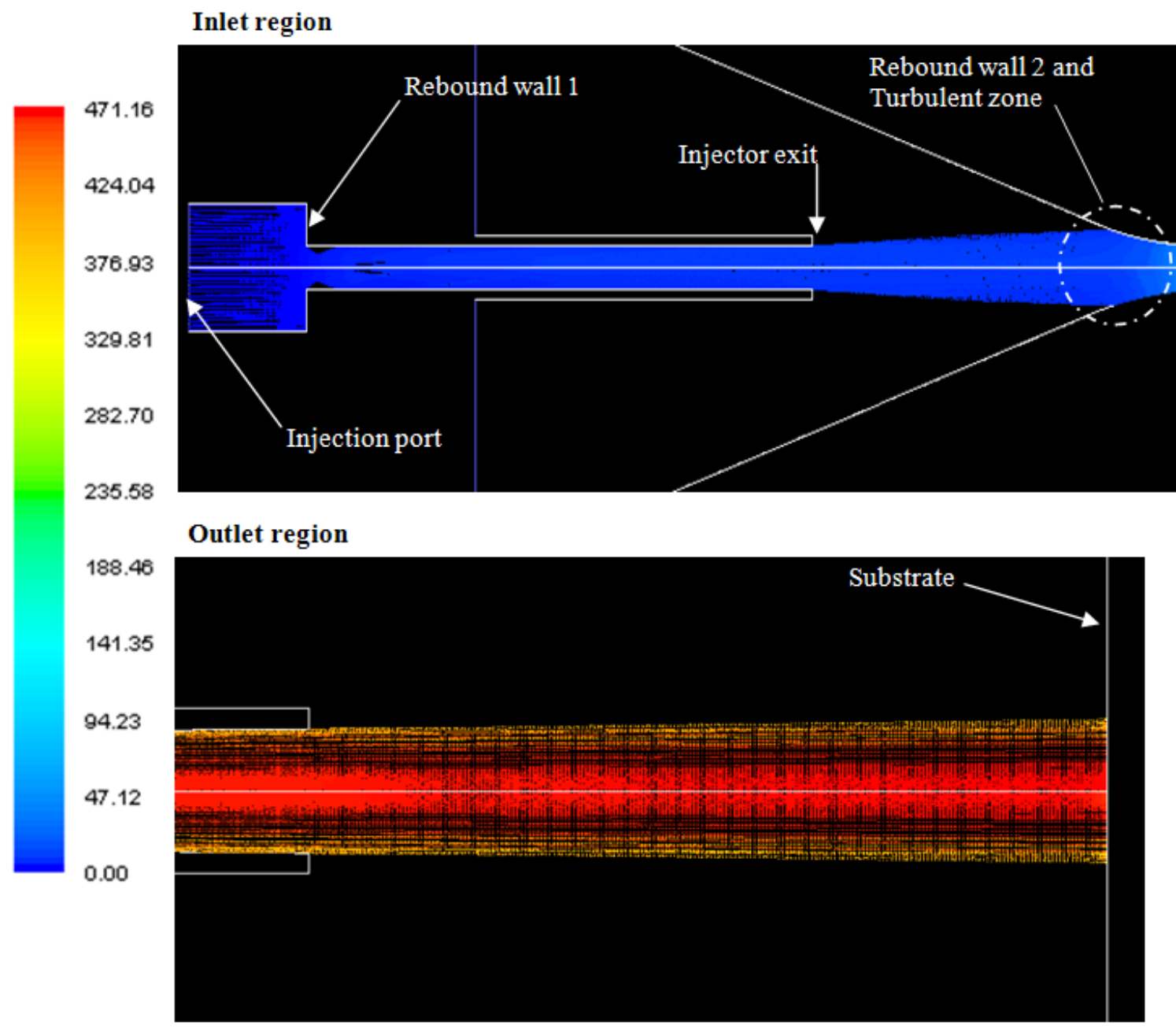

Figure 6: CFD particles stream, $20 \mu \mathrm{m}$ copper, coloured by velocity magnitude $(\mathrm{m} / \mathrm{s})-$ configuration (1) 


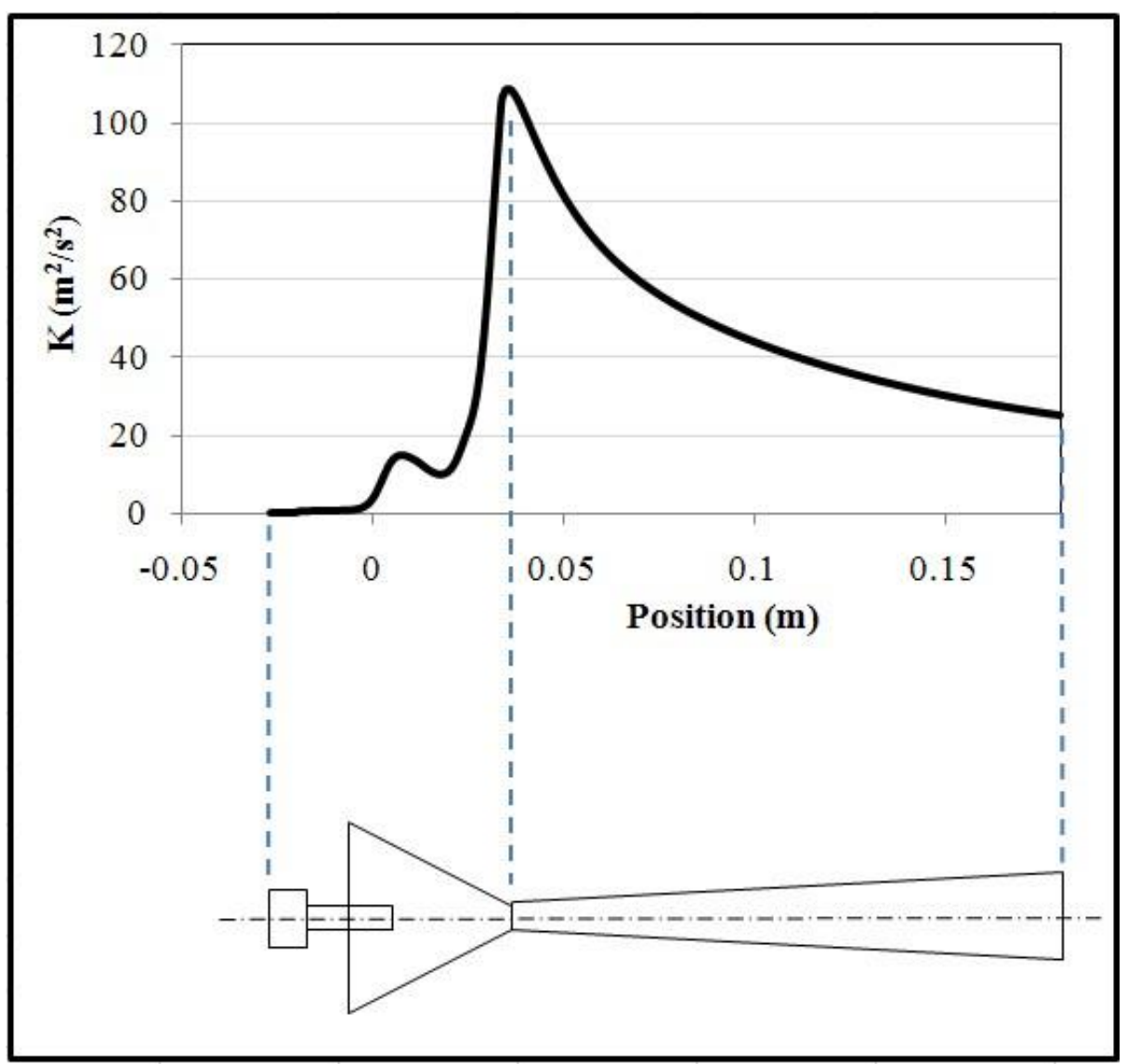

Figure 7: CFD specific turbulence kinetic energy (K) against nozzle centreline configuration (1) 


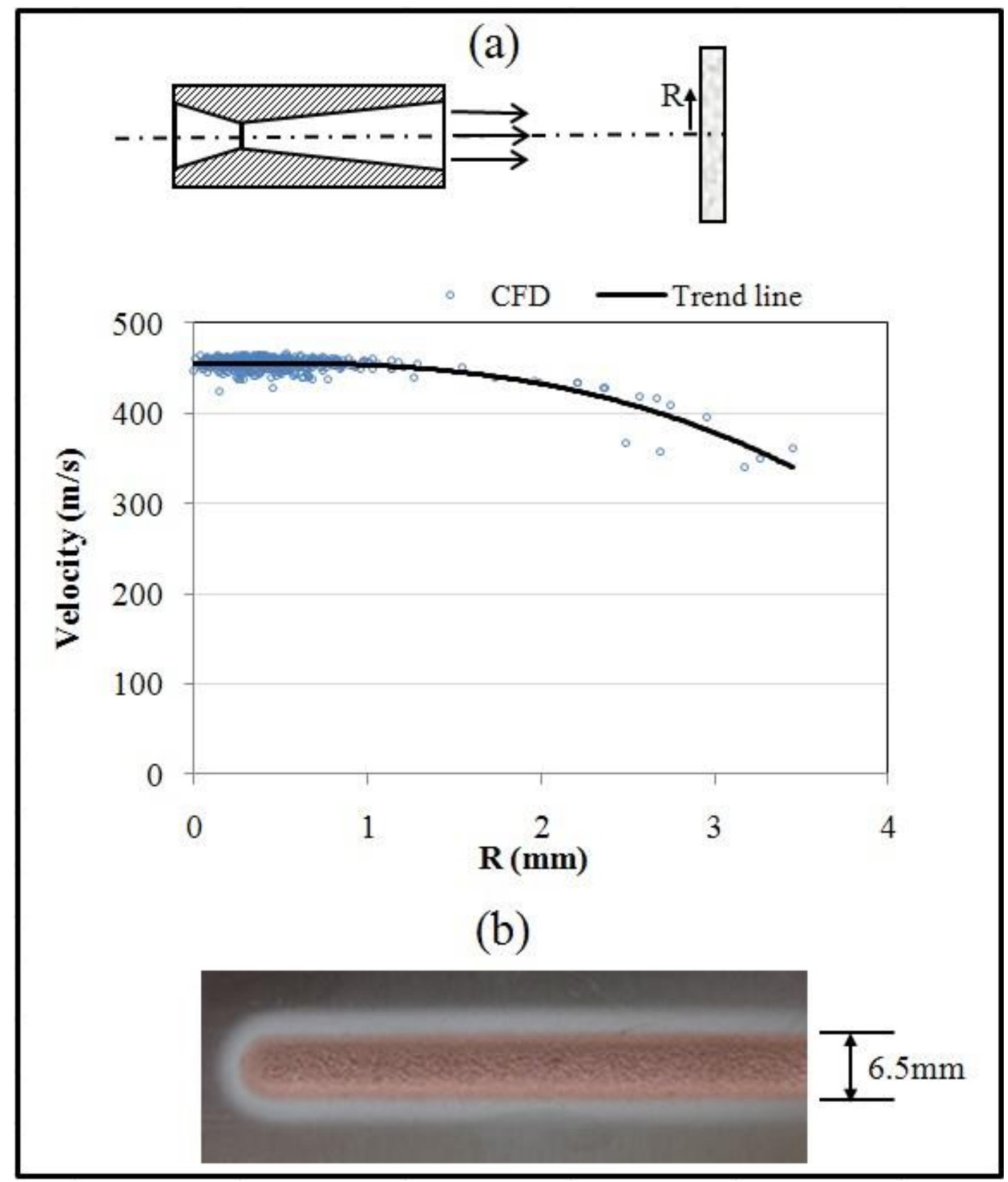

Figure 8: (a) CFD particle stream distribution, 20 $\mu \mathrm{m}$ copper, against impact velocity over the substrate surface - configuration (1). (b) Experimental copper track on aluminium for configuration (1) 
Figure 9: CFD particles stream, $20 \mu \mathrm{m}$ copper, coloured by velocity magnitude $(\mathrm{m} / \mathrm{s})-$ configuration (2)

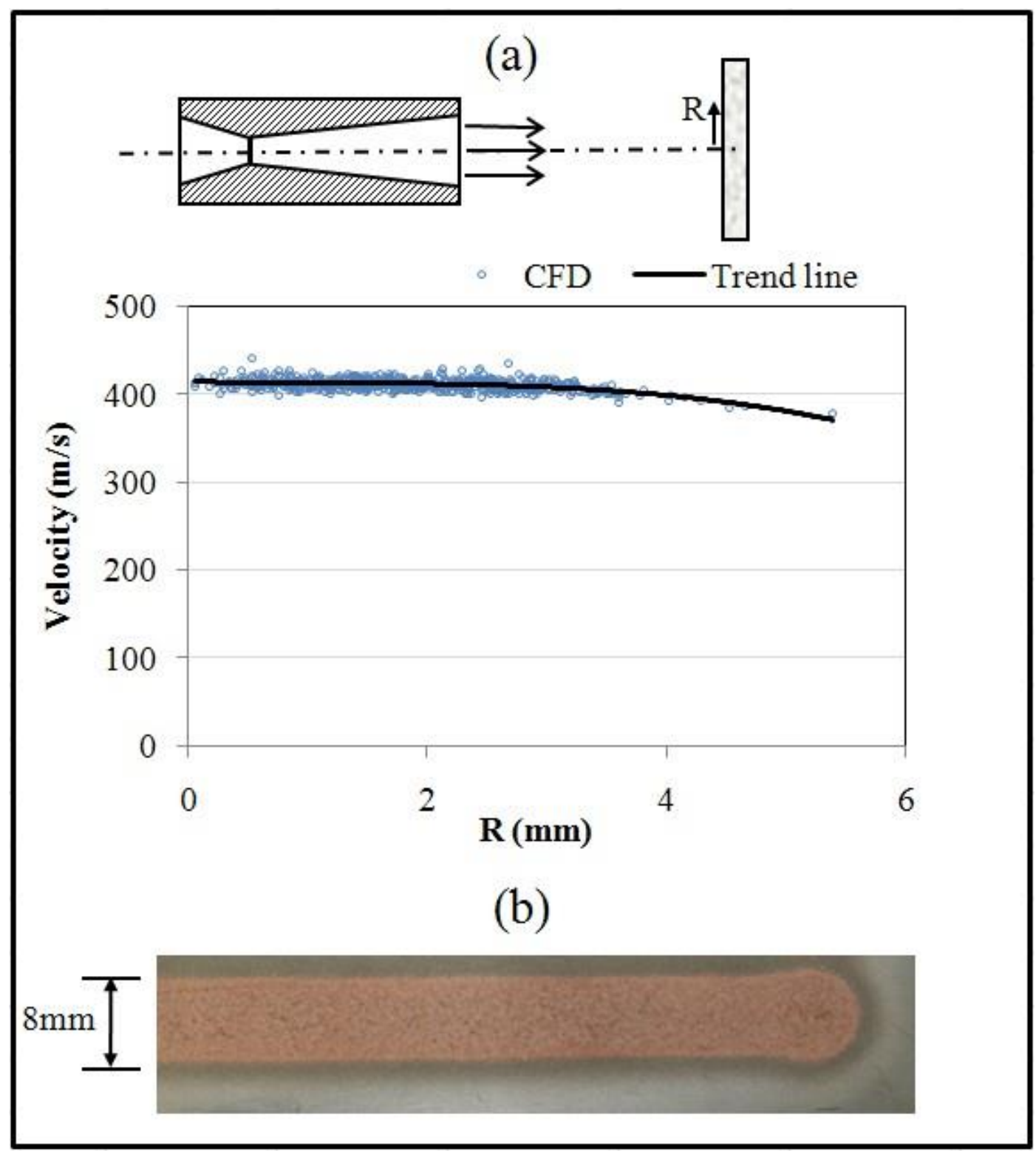


Figure 10: (a) CFD particle stream distribution, 20 $\mu \mathrm{m}$ copper, against impact velocity over the substrate surface - configuration (2). (b) Experimental copper track on steel for configuration (2)
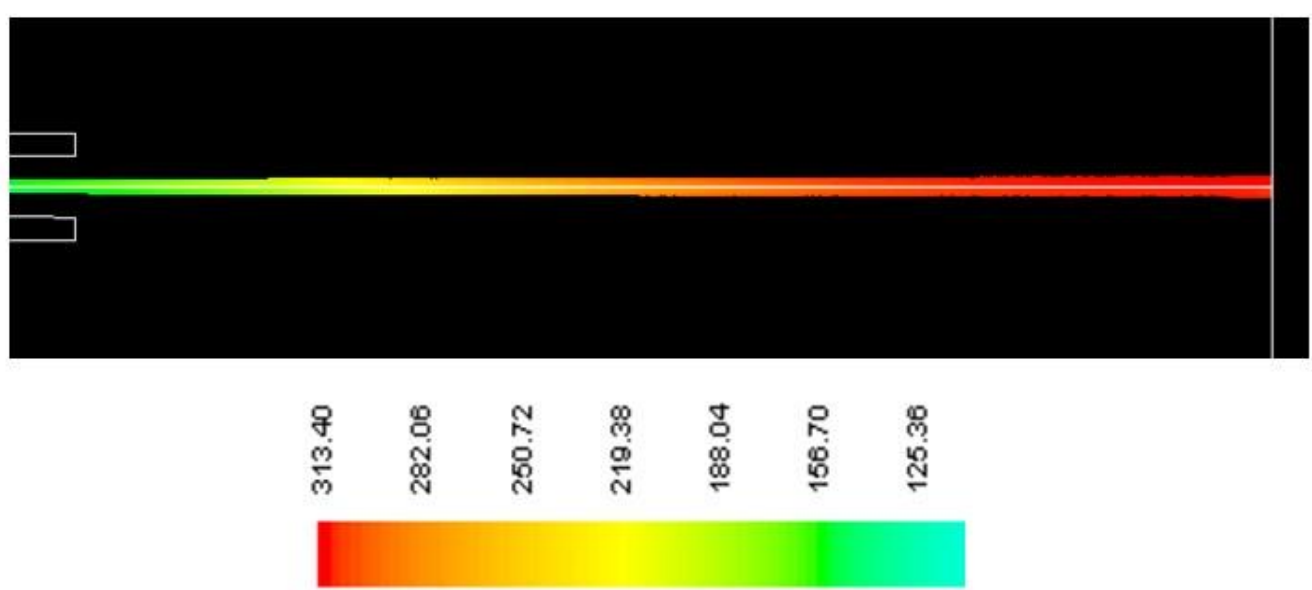

Figure 11: CFD particles stream, $20 \mu \mathrm{m}$ tin, coloured by velocity magnitude $(\mathrm{m} / \mathrm{s})-$ configuration (3)

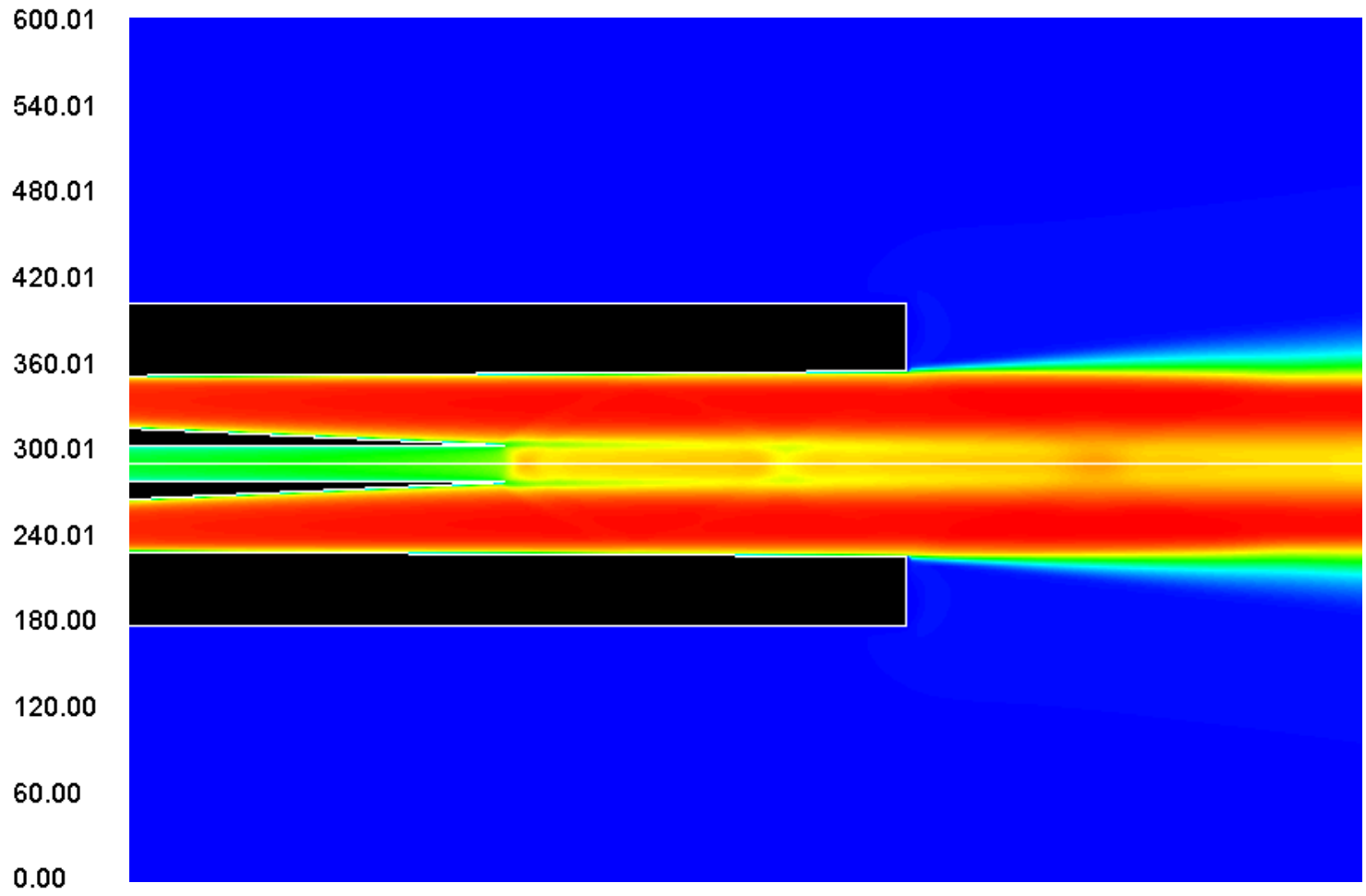


Figure 12: Plot of velocity magnitude contours $(\mathrm{m} / \mathrm{s})$ at the injector exit location configuration (3)

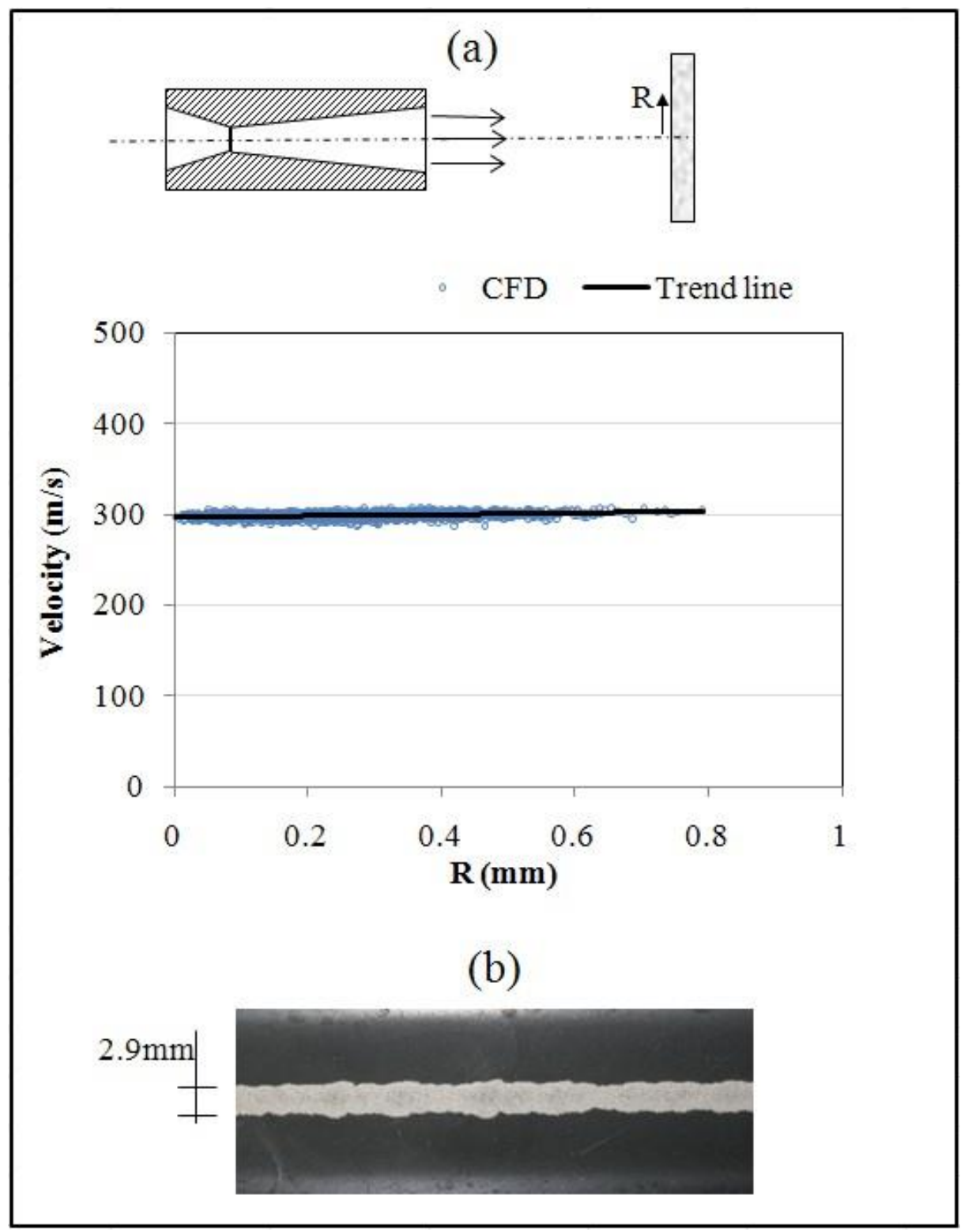

Figure 13: (a) CFD particle stream distribution, $20 \mu \mathrm{m}$ tin, against impact velocity over the substrate surface - configuration (3). (b) Experimental tin track on PC/ABS for configuration (3) 


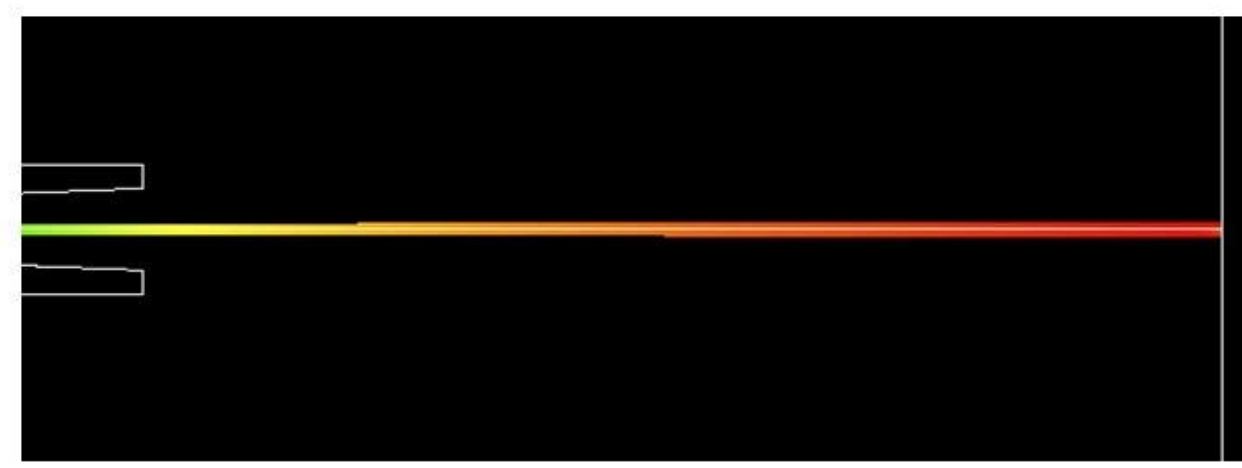

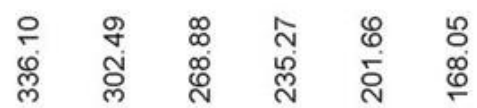

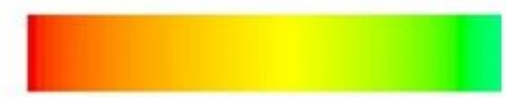

Figure 14: CFD particles beam, $20 \mu \mathrm{m}$ tin, coloured by velocity magnitude $(\mathrm{m} / \mathrm{s})-$ configuration (4)

243.59

182.69

121.80

60.90

0.00

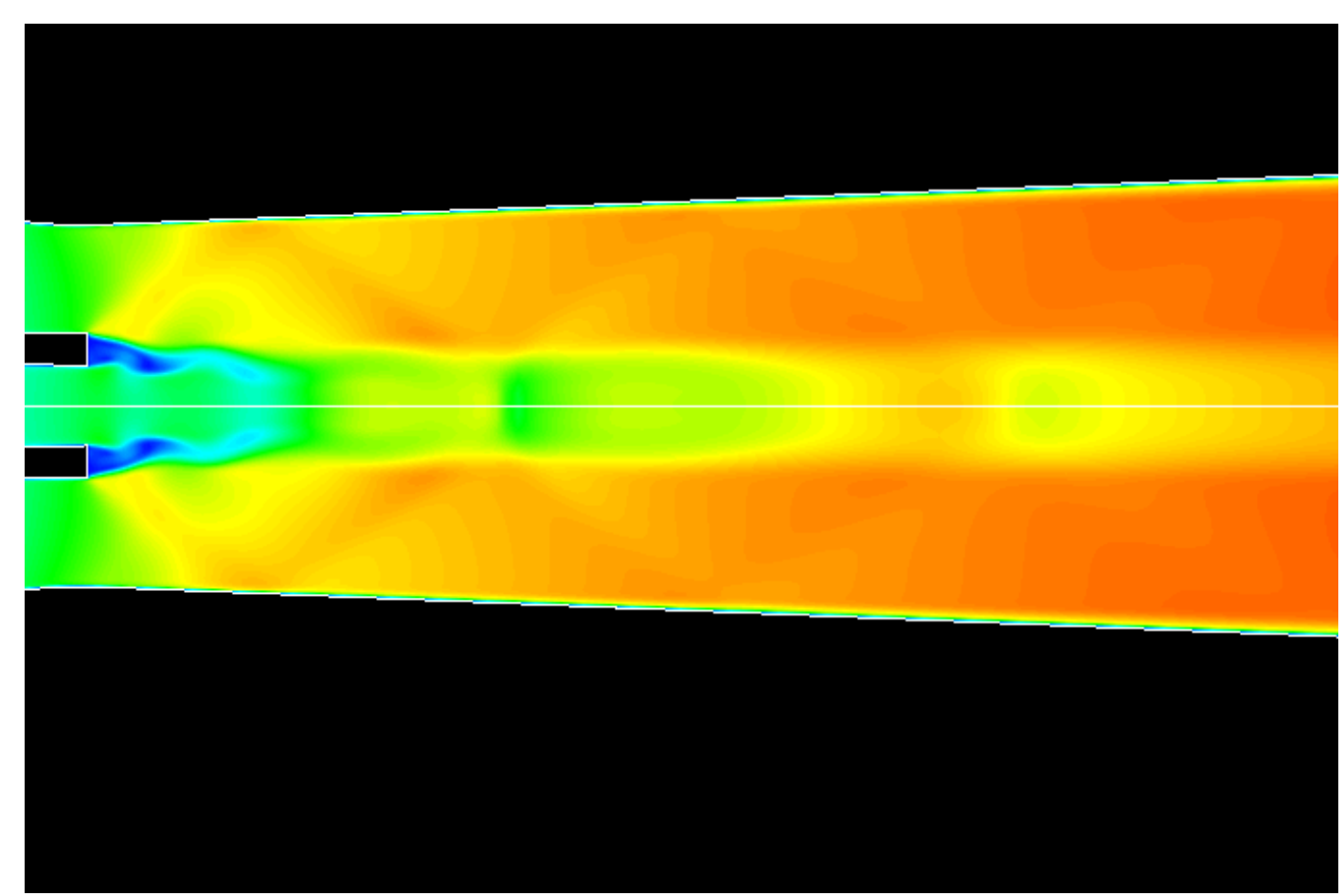


Figure 15: Plot of velocity magnitude contours $(\mathrm{m} / \mathrm{s})$ at the injector exit location configuration (4)

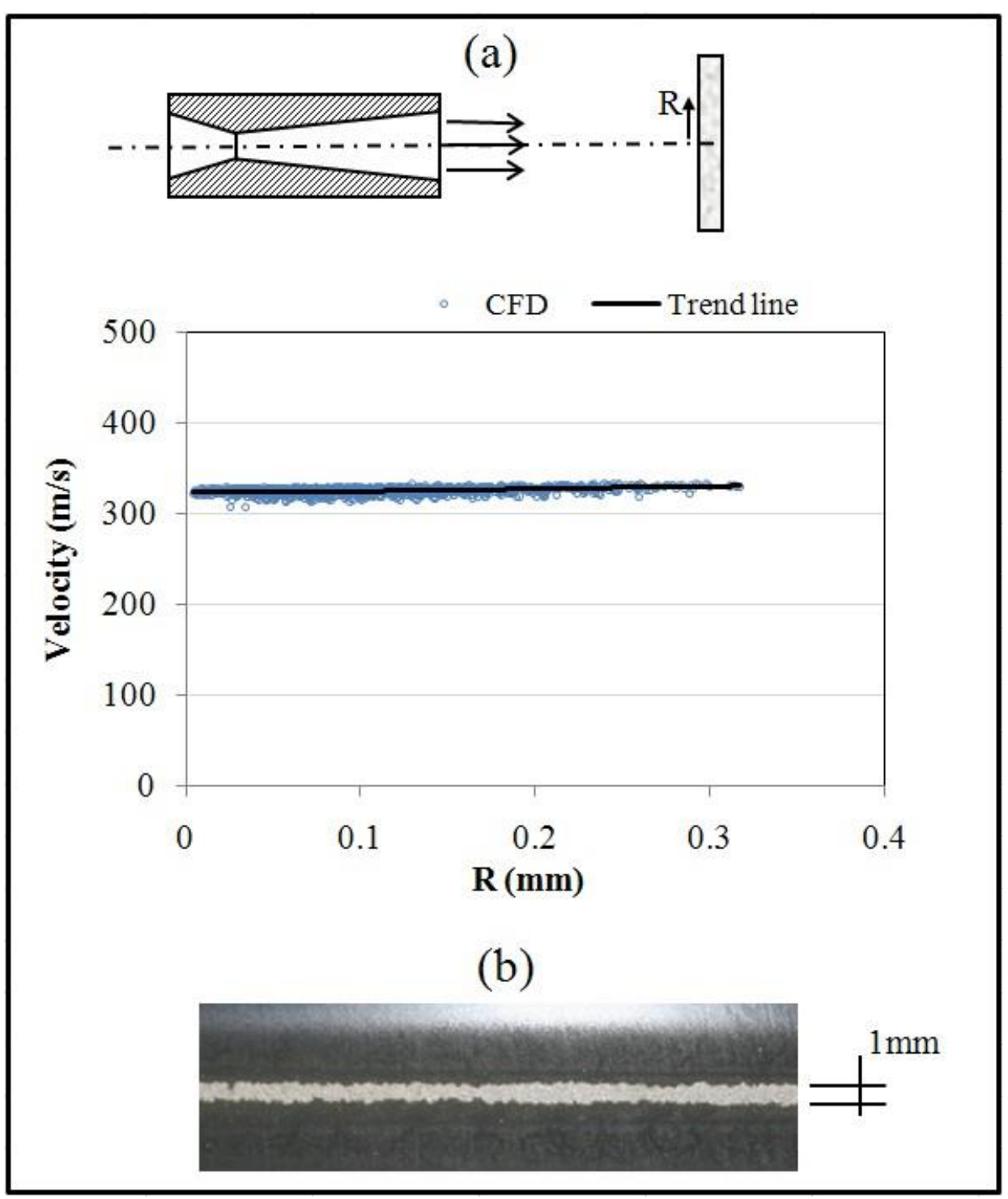

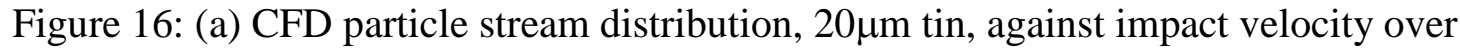
the substrate surface - configuration (4). (b) Experimental tin track on PC/ABS for configuration (4)

\begin{tabular}{|c|c|c|c|c|}
\hline CONFIGURATION & $\mathbf{1}$ & $\mathbf{2}$ & $\mathbf{3}$ & $\mathbf{4}$ \\
\hline$d=10 \mu m$ & 2.5 & 10.6 & 1.6 & 0.7 \\
\hline$d=20 \mu m$ & 6.9 & 10.7 & 1.6 & 0.6 \\
\hline$d=32 \mu m$ & 7.1 & 13.4 & 1.7 & 0.9 \\
\hline
\end{tabular}


Table 2: CFD prediction of particles footprint diameter $(\mathrm{mm})$ on the substrate at variable particle size 